Gut, 1969, 10, 831-837

\title{
Severe peptic oesophagitis
}

\author{
P. L. BRUNNEN, A. M. KARMODY, AND C. D. NEEDHAM \\ From the Thoracic Surgical Unit and the Gastroenterological Records Unit, Aberdeen General Hospitals, \\ Aberdeen
}

SUMMARY The incidence, clinical and investigative features, treatment, and course of severe oesophagitis in 200 patients seen and followed up in the Thoracic Surgical Department for north east Scotland from 1951 to 1967 are reviewed. The male/female ratio was $1 / 1.9$. The incidence of severe oesophagitis (grades III and IV) approximated to 4.5 per 100,000 ; there was a dramatic increase from the age of 50 years onwards.

Reflux, with or without hiatal hernia, precedes oesophagitis and has an incidence in excess of 86 per 100,000 . It is difficult to assess the extent to which reflux produces mild oesophagitis, but it is clear that it only infrequently leads to the severe grades.

Severe oesophagitis does not always need operative treatment. A conservative regime, supplemented by bouginage as required, enables the poorer-risk older patient to live a near-normal life span, in very reasonable comfort. Fifty-three patients of the whole series were operated upon, half primarily and half after previous conservative treatment. The problems of operative treatment are discussed. Newer procedures designed to prevent reflux now allow operation to be more freely advised.

Perhaps, rather surprisingly, severe oesophagitis had very little effect on the expectation of life, whether treatment was conservative or operative.

Peptic oesophagitis arises from reflux of gastric contents into the oesophagus as a result of incompetence of the cardia. It extends proximally from the gastrooesophageal junction and may be classified in four grades of severity (Skinner and Belsey, 1967). In grade I oesophagitis there is mucosal redness. In grade II there is isolated or scattered superficial ulceration, sometimes running up between the longitudinal folds. In grade III oesophagitis there is chronic ulceration, with infiltration and thickening deep to the ulcer and frequently circumferential; the oesophagus is often shortened. In grade IV there is fibrous stricture formation; there may be chronic ulceration at or proximal to the gastrooesophageal junction, and the oesophagus usually shows fibrous shortening.

This paper is concerned with grades III and IV oesophagitis ('severe oesophagitis'). We review the management and response to treatment of our own patients, and discuss the numerical relationship of severe oesophagitis to its main predisposing conditions.

There were 200 such patients treated during the period summer 1951 to spring 1967 in the Aberdeen
Thoracic Surgical Unit of the North Eastern Hospital Region (Scotland). This unit serves its own region (mainland plus the Orkney and Shetland Islands) and to some extent also the Northern Hospital Region (Scotland). The administrative arrangements during the period of this review were such that most patients admitted from this geographical area with severe oesophagitis reached the Thoracic Surgical Unit. In this period only about 25 patients with severe oesophagitis confirmed by oesophagoscopy were dealt with outside this unit. Children aged less than 12 years were excluded from the survey.The diagnosis was made by oesophagoscopy carried out in this department. All patients had barium meal examinations. The follow up was by regular outpatient appointments and readmissions as necessary. Information about surviving patients discharged from review was obtained through family doctors and from patients themselves. The relationship of severe oesophagitis to other upper alimentary lesions was studied after we had analysed the results of the 4,828 routine upper gastrointestinal barium examinations carried out in the whole North Eastern Hospital Region (population 
$485,000)$ during 1967 . This material will be referred to as the North East of Scotland (1967) Barium Survey.

INCIDENCE

Because of problems of distance, and other factors, we think it unlikely that referrals from the Northern Region and Islands (Orkney and Shetland) could be regarded as complete, so that, in estimating incidence we decided to consider north east mainland patients only. The referral rate for this area rose steadily from 1951 to 1962 , but then levelled off to yield 88 cases evenly spread over the last five years. During the same period 12 other cases from the same area were dealt with by surgical colleagues. These 100 patients, seen over a five-year period in a population of 443,000 , give an approximate annual incidence of 4.5 per 100,000 . We believe that underestimation of incidence will be small, as most patients with severe oesophagitis, and without travel difficulties, will reach hospital.

The age incidence of severe oesophagitis shows a marked increase in middle and later life (Fig. 1).

\section{CLINICAL AND INVESTIGATIVE FEATURES}

Nearly all patients had symptoms typical of reflux oesophagitis, eg, heartburn with postural aggravation, regurgitation, and dysphagia. Analysis of the previous duration of significant symptoms shows that in $18 \%$ of the cases it was less than one year and in $50 \%$ less than three years; however, in $24 \%$ it exceeded 10 years. The duration was unrelated to the presence of stricture, to sex, or to age at the time of diagnosis. Sex distribution and results of examinations are shown in Table I.

Because the development of a fibrous stricture is such an important feature, indicating greater severity of the problem as a whole, the further

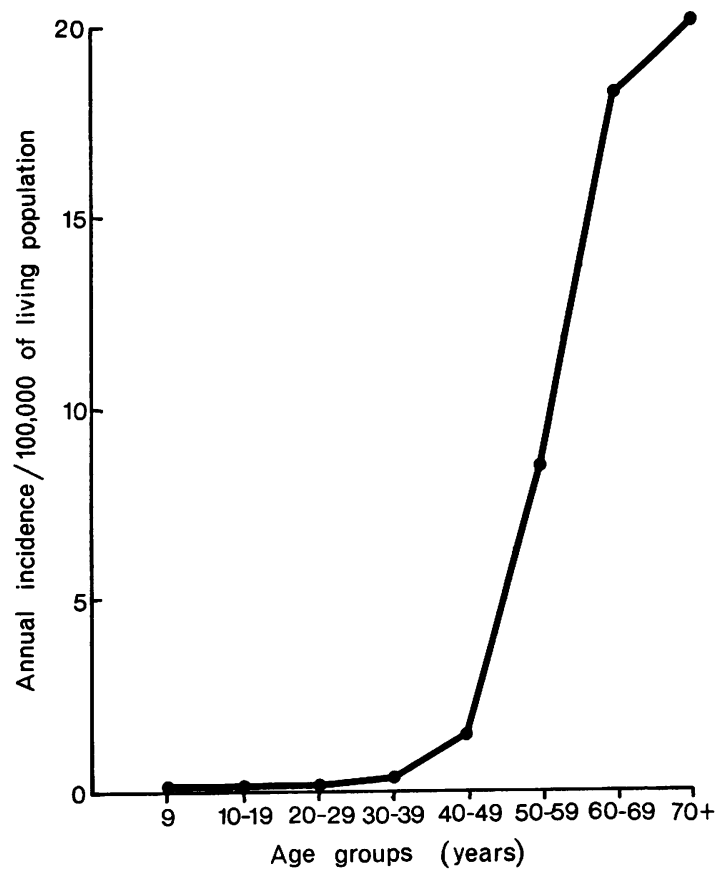

FIG. 1. Severe peptic oesophagitis. Annual incidence per 100,000 of living population in each age group.

analysis of the findings has been related to whether or not a stricture was present. Dysphagia has been included here to show that it may be present without stricture or denied even when there is a stricture.

The finding of severe oesophagitis at our initial oesophagoscopy determined the inclusion of the case within the series. Stricture was present in 158 patients $(79 \%)$ and of these $110(70 \%)$ showed oesophagitis proximal to the stricture; this proximal oesophagitis indicated that reflux was still occurring

TABLE I

INITIAL EXAMINATION FINDINGS

\begin{tabular}{|c|c|c|c|c|c|c|c|c|c|c|c|}
\hline \multirow{4}{*}{$\operatorname{Sex}$} & \multirow{4}{*}{$\begin{array}{l}\text { Presence or Absence } \\
\text { of Stricture }\end{array}$} & \multirow{4}{*}{ Total } & \multirow{4}{*}{ Dysphagia } & \multirow{2}{*}{\multicolumn{2}{|c|}{ Oesophagoscopy }} & \multirow{2}{*}{\multicolumn{6}{|c|}{ Barium Meal }} \\
\hline & & & & & & & & & & & \\
\hline & & & & \multirow[t]{2}{*}{ Stricture } & \multirow[t]{2}{*}{$\begin{array}{l}\text { Severe } \\
\text { Oesophagitis }\end{array}$} & \multirow[t]{2}{*}{ Reflux } & \multirow[t]{2}{*}{ Narrowing } & \multicolumn{2}{|c|}{ Hiatal Hernia } & \multirow{2}{*}{$\begin{array}{l}\text { Duodenal } \\
\text {-Ulcer }\end{array}$} & \multirow[t]{2}{*}{$\begin{array}{l}\text { Report } \\
\text { Lost }\end{array}$} \\
\hline & & & & & & & & $\begin{array}{l}\text { Axial or } \\
\text { Sliding }\end{array}$ & Combined $^{1}$ & & \\
\hline $\begin{array}{l}\mathbf{M} \\
\mathbf{M} \\
\mathbf{M} \\
\mathbf{F} \\
\mathbf{F} \\
\mathbf{F}\end{array}$ & $\begin{array}{l}\text { No stricture } \\
\text { Stricture } \\
\text { Total } \\
\text { No stricture } \\
\text { Stricture } \\
\text { Total }\end{array}$ & $\begin{array}{r}15 \\
56 \\
71 \\
27 \\
102 \\
129\end{array}$ & $\begin{array}{r}11 \\
48 \\
59 \\
19 \\
91 \\
110\end{array}$ & $\begin{array}{r}0 \\
56 \\
56 \\
0 \\
102 \\
102\end{array}$ & $\begin{array}{l}15 \\
38 \\
53 \\
27 \\
72 \\
99\end{array}$ & $\begin{array}{r}5 \\
18 \\
23 \\
21 \\
46 \\
67\end{array}$ & $\begin{array}{r}5 \\
34 \\
39 \\
7 \\
65 \\
72\end{array}$ & $\begin{array}{r}10 \\
36 \\
46 \\
24 \\
77 \\
101\end{array}$ & $\begin{array}{l}1 \\
0 \\
1 \\
0 \\
3 \\
3\end{array}$ & $\begin{array}{l}1 \\
8 \\
9 \\
3 \\
6 \\
9^{2}\end{array}$ & $\begin{array}{l}2 \\
2 \\
4 \\
2 \\
4 \\
6\end{array}$ \\
\hline Total & & 200 & 169 & 158 & 152 & 90 & 111 & 147 & 4 & $18^{2}$ & 10 \\
\hline
\end{tabular}

1'Combined' means 'axial' plus 'paraoesophageal'.

${ }^{2}$ Includes four patients with pyloric stenosis. 
through the stricture, although it was not seen to occur radiologically in almost half of this particular group. In the absence of fibrous stricture there was chronic ulceration.

Reports of the 200 initial barium studies were available in only 190 cases, and these are analysed. Oesophageal narrowing was undisclosed in $33 \%$ of those with proved stricture, while it was reported as present, possibly because of spasm or oedema, in $33 \%$ of those who did not have a stricture. Reflux, which had presumably been causative at some stage in all cases, was shown in only $47 \%$. Hiatal hernia, nearly always axial and never strictly paraoesophageal, was shown in $80 \%$. Duodenal ulcer was noted in $12.7 \%$ of the men and $7 \%$ of the women; it was complicated by pyloric stenosis in only four patients, all women. No gastric ulcers were seen.

\section{TREATMENT AND PROGRESS}

This applies to management and progress from the time of oesophagoscopic diagnosis of severe oesophagitis. For analysis, the patients have been grouped into those being assessed and managed on a medical regime, those having a medical regime plus bouginage, and those treated surgically whether by primary choice or after a trial of conservative treatment. Figures 2, 3, and 4 present this information graphically. The estimates of quality of the symptomatic results cannot be precise, but in deciding the category for each patient careful note was taken of all available evidence.

MEDICAL REGIME Management included sleeping with the bed-head raised 10 inches, avoiding activities that involve much bending, and avoiding tight corseting. Alkaline tablets were prescribed. Much importance was attached to reduction of obesity. Of 25 patients without fibrous stricture who began in this group (Fig. 2a), seven later required operation and were transferred to the 'surgical (failed conservative treatment)' group in which they are now assessed (Fig. 4). Of the residual 18 followed for varying periods, five died of conditions unrelated to the oesophagitis, four were 'not improved', and nine were 'much improved'.

Medical Regime plus bouginage This included dilatation by gum elastic bougies at oesophagoscopy, involving two nights in hospital. When necessary, repeat dilatations were done at gradually increasing intervals, sometimes exceeding one year. In 12 cases initial oesophagoscopic dilatation was followed by regular self-bouginage with mercury-filled rubber bougies. However, in general, our patients did not take kindly to self-bouginage.

Of 149 patients who began in this group, 20 were later transferred to surgery (Fig. 4). Of the residual 129 (Fig. 2b), 44 died; six deaths were mainly attributable to oesophagitis (five occurring within two years of diagnosis); another patient died from the only instrumental perforation in the series. The periods survived by the 44 fatal cases are shown in Figure 3. Eight patients were 'not improved' but 77 were 'much improved'. A separate analysis of the 129 in this group shows that, of the 64 who were followed for more than four years, $37(58 \%)$ did not require dilatation of any kind during the last two years of their follow up.

SURGICAL (OPERATIVE) TREATMENT There were 26 patients treated primarily by operation (Fig. 2c) and 27 who came to surgery after varying periods of conservative treatment (Figs. 2a, 2b, and 4). These two groups did not differ significantly in other respects, and the following remarks apply to the two groups considered together.

Operation was limited to simple repair in 29. In 21 other patients, 12 of the operations were hernial repairs accompanied by vagotomy and gastric drainage (usually pyloroplasty), and nine were procedures such as oesophagogastrectomy and oesophagogastrostomy. Three who had initial operations at other centres had second operations of various types done here. Of the 53 surgical patients nine died, four from operation (three cardiorespiratory failures, and one anastomotic leak), one after 11 years of unsatisfactory progress, and four from unrelated causes. Seven were 'not improved' and 37 were 'much improved'.

Only three of 16 patients with fibrous stricture followed for more than four years postoperatively needed dilatation during the last two years before assessment.

There was a history of severe bleeding in 11 of the 200 patients. Six of these were female and had no lesion other than oesophagitis; in the five males there was also duodenal ulcer in four and stomal ulcer in the fifth. Bleeding was not seen at operation and the source of haemorrhage could not be proved.

\section{EFFECT ON LONGEVITY}

Most of our patients at the time of follow up had not as yet completed their life span. We theretore adopted the method of calculating how many would have been expected, on the experience of the general population of Scotland, to be alive at the time of follow up. Life tables published by the Registrar General for Scotland were used. The 1961 table was chosen because it lay in time reasonably near the 

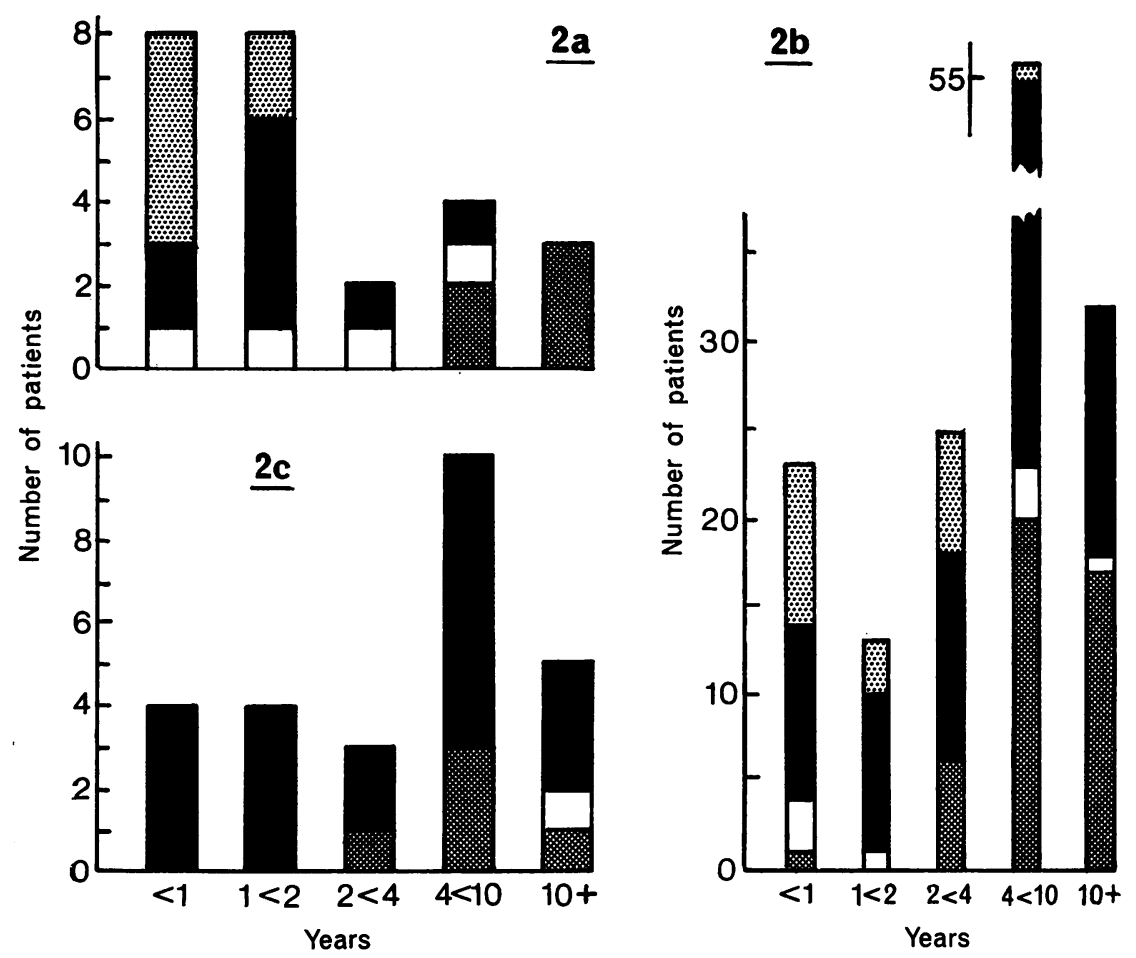

FIG. 2. Treatment and progress. Columns indicate numbers of patients and results, grouped according to years elapsing from date of diagnosis to end of survey (or date of transfer to surgery).

Failed Conservative treatment transferred to Surgical (Fig 4)
Much improved

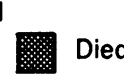

FIG. 3. Medical plus bouginage. Periods survived by the 44 fatal cases. Deaths related to oesophagitis are shown by lighter hatching.

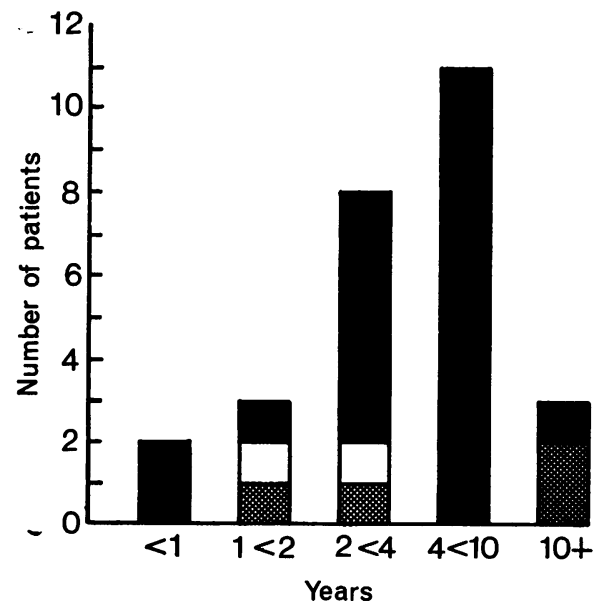

FIG. 4. Surgical (failed conservative treatment). Numbers of patients and results are grouped according to years from date of operation to end of survey (shading as in Fig. 2). 
middle of the whole series and any error resulting from using this single table for all cases would appear to be negligible. From it were calculated the individual probabilities of being alive at the time of follow up. These values were summed, and comparisons were made for the various groups between first, the numbers actually surviving, and, second the numbers expected to be surviving, at the time of follow up. Table II shows the results of these longevity calculations for the whole series and for each of the treatment groups, surgical cases being taken as one group. For the numbers in the present series the decrease in life expectation does not reach

TABLE II

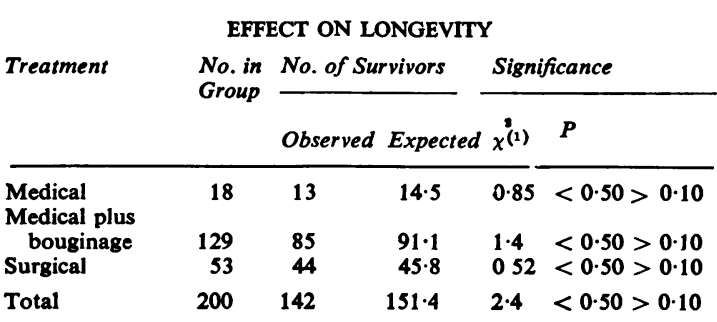

significance at the $5 \%$ level; yet it is consistent throughout the groups and is presumably real, though not large. Longevity is not, of course, the only feature of importance; some indication of the quality of survival is shown in Fig. 2, but this does not illustrate the increasing freedom from trouble found in all three groups with the passage of time.

\section{DISCUSSION}

INCIDENCE A search of the literature has yielded little information about the incidence of oesophagitis in a general population, as opposed to its incidence in selected groups of patients usually suffering from hiatal hernia. However, figures for hiatal hernia, and even more for reflux, are evident understatements because of the well recognized difficulties in demonstrating these lesions radiologically and because barium screening seldom samples more than $1 \%$ of a population. Reflux is often found without hiatal hernia; this was the case in $25 \%$ of all those shown to have gastrooesophageal reflux in the North East of Scotland (1967) Barium Survey. Furthermore, the average age of those with reflux was less than that for hiatal hernia in the same survey, and also less than that for established oesophagitis in the present series. This suggests that reflux precedes hiatal hernia, and is in keeping with the view that reflux, rather than hiatal hernia, is the important precursor of oesophagitis (Hiebert and Belsey, 1961; Brain, 1966; Johnson, 1968). It is uncertain how many patients suffering from reflux develop some degree of oesophagitis. Most studies of the incidence of oesophagitis have been in relation to hiatal hernia, often without reference to the degree of oesophagitis. From many published series it seems that severe oesophagitis occurs in 15 to $25 \%$ of cases of axial hernia seen in surgical departments, but considering the usual manner of referral it seems that selectivity has played a quite misleading part. This has led to exaggeration of the extent to which severe oesophagitis results from axial hernia and reflux. Here, in a closed 'mainland' population of 443,000 , we have estimated that severe oesophagitis occurred in only 4.5 per 100,000 per annum, whereas the real incidence of gastrooesophageal reflux must substantially exceed the figure of 86 per 100,000 which emerges from the North East of Scotland (1967) Barium Survey. It appears that severe oesophagitis occurs in considerably less than $5 \%$ of patients with oesophageal reflux.

As the milder grades of oesophagitis must be much commoner, and as life expectation is only slightly impaired by severe oesophagitis, however treated, it follows that not many of the mild cases can be progressive for otherwise there would be a much larger pool of still-surviving severe cases, many with stricture.

TREATMENT OF REFLUX WITHOUT SEVERE OESOPHAGITIS These estimates of relative incidence must lead to a reappraisal of the management of oesophageal reflux, with or without hiatal hernia, and with particular reference to indications for surgery. There should be little enthusiasm for purely prophylactic operations on the very large number of patients with reflux and/or hiatal hernia but without severe oesophagitis. The great majority of such operations would be unnecessary. This view is supported by the benign course observed during the 10 years of a study of medically treated hiatal hernia (Rex, Andersen, Bartholomew, and Cain, 1961).

We believe that if symptoms are mild and oesophagoscopy discloses only minimal oesophagitis, or none at all, one cannot justifiably use the fear of future severe oesophagitis as a sufficient reason for advising operation on the large number of hiatal hernia patients seen at this stage. There may, of course, be other factors swaying the decision towards operation. Such a patient, but with severe symptoms persisting after a year on an adequate medical regime, and especially if the symptoms are provoked by instillation of weak acid into the oesophagus (Bennett and Atkinson, 1966), will ordinarily need surgery to stop the reflux. An operation of the type described by Nissen (1964) or by Skinner and Belsey (1967) is very suitable. 
CONSERVATIVE TREATMENT OF SEVERE OESOPHAGITIS There has been no general agreement on the best treatment for established oesophagitis. In most cases (79\% in the present series) stricture is already present, requiring a decision between bouginage and operation. The changing pattern and variety of operations advised by others through the years of this survey did not encourage us to recommend surgery to older patients. We preferred to carry them along with simple medical measures supplemented by bouginage, in most cases of oesophagoscopy. An obvious criticism was that it required repeated oesophagoscopies, with the risk both of the procedure itself and of the anaesthetic; but in this series there was only one instrumental fatality in the bouginage group. The brief stay in hospital gave a good opportunity for periodical review and proved acceptable to the patient. The results, as regards both quality and expectation of life, were reasonable. The slightness of the effect of severe oesophagitis upon life expectancy was especially noteworthy in relation to those treated by intermittent bouginage. Of the 44 deaths in this group over the whole period of the survey, only seven were directly related to the oesophageal condition. This marked preponderance of unrelated deaths is in keeping with the observation that the average age at diagnosis was about six years higher for the fatal cases than for the survivors. However, this conservative form of treatment is not approved by some (Barrett, 1962; Belsey, 1966; Tanner, 1966). It has also been suggested (Truelove and Reynell, 1963; Davidson, 1968) that oesophagitis predisposes to carcinoma of oesophagus. This was not seen in the present series, and evidence of antecedent oesophagitis was found in only four of 357 consecutive cases of carcinoma of the oesophagus treated in this unit. Any association would appear to be too slight for it to influence the choice of treatment of severe oesophagitis. It is still our view that a considerable number of elderly patients are best treated by repeated bouginage, but improved surgical procedures and results have latterly made us adopt a more aggressive attitude in the somewhat younger and fitter patients.

OPERATIVE TREATMENT OF SEVERE OESOPHAGITIS It was recognized that operation was necessary in some patients, and more than a quarter of this series were so treated. The commonest procedure was an Allison (1951) repair operation or a modification of that. Other operations employed are referred to earlier under 'Treatment and progress'. The uncertainty of all these procedures, practised during this formative period for surgical treatment of reflux, is well described by Johnson (1968). The more recently developed operations (Hiebert and Belsey, 1961; Nissen, 1964) are much more efficient in preventing reflux.

Uncomplicated severe oesophagitis in a reasonably fit person should usually be treated by such an operation; we agree with Hill (1967) that there is no justification for adding vagotomy and drainage in the absence of duodenal ulcer. In many cases, however, it will be impossible to reduce the lower end of the oesophagus into the abdomen; for these we have recently preferred to use the Nissen fundoplication procedure within the left chest; its antireflux principles apply despite irreducibility of the hernia, and early clinical results have been encouraging.

If there is a fibrous stricture the problem is more difficult. Widespread use of resection, with interposition of colon, might well lead to a significant mortality. We adopt a cautious approach to a condition which, as has been shown, does not in itself greatly shorten life. The poorer-risk older patient is treated by intermittent bouginage, if possible. Operation is reserved for the better-risk patients and for those responding poorly to bouginage. In these, if the stricture is not severe, an antireflux operation is done; the Nissen operation is preferred because, for reasons explained in the previous paragraph, it seems very suitable for these cases, where the hernia is usually irreducible. Although local changes associated with fibrous stricture must partly or wholly destroy the function of the intrinsic muscle of the cardia, we have seen such strictures resolve slowly but almost fully after operative elimination of reflux. This occurred in 13 out of 16 such patients, followed up for more than four years postoperatively and not needing dilatation of stricture during the last two years of follow up. Resection with colon replacement is therefore reserved for those with virtually complete stricture, although even here there may be a place for the more conservative operation recommended by Thal, Hatafuku, and Kurtzman (1965).

We have not found the high incidence of association with duodenal ulcer reported by some others (Berne, 1964; Wolf, 1967). Indeed, our finding of associated duodenal ulcer in $12.7 \%$ of men and $7 \%$ of women is little different from the prevalence rate of $10 \%$ for duodenal ulcer observed in adult men in one general practice in the north east of Scotland (Weir and Backett, 1968). Among the 590 patients found to have hiatal hernia in the North East of Scotland (1967) Barium Survey, $28 \%$ of males and $7 \%$ of females had an associated gastric or duodenal ulcer. This figure for males is twice as high as in our own group of patients with severe oesophagitis, which suggests that a male with hiatal hernia is not 
more likely to develop severe oesophagitis if he has an associated duodenal or gastric ulcer. This argues against the suggestion by Burge, Gill, MacLean, and Lewis (1966) that lesions of the pyloric canal and duodenum precipitate oesophagitis in patients with hitherto quiescent hiatal hernia. However, when duodenal ulcer does exist with oesophagitis, we believe that vagotomy and gastric drainage, usually pyloroplasty, should be included in the operative procedure.

In the presence of severe oesophagitis with or without stricture, severe bleeding, whether acute or chronic, ordinarily demands operation. If the haemorrhage is oesophageal it usually suffices to treat the problem as one of hiatal hernia with reflux. If it is from a gastroduodenal lesion the total operative procedure must include control of that source.

We are grateful to the North Eastern Regional Hospital Board (Scotland) which supports the Gastroenterological Records Unit. We owe much to the secretarial help of Mrs M. C. Smith and Mrs D. Bell. Mr F. J. Sambrook Gowar has allowed us to include those of the patients who were under his care, and we thank him and Sister C. K. Taylor of the Thoracic Surgical Unit. Through the courtesy of Dr L. A. Gillanders we have had access to radiological records. We gladly acknowledge the willing cooperation of the general practitioners. The illustrations were kindly prepared by Mr D. P. Hammersley, Head of the Department of Medical Illustration.

\section{REFERENCES}

Allison, P. R. (1951). Reflux esophagitis, sliding hiatal hernia, and the anatomy of repair. Surg. Gynec. Obstet., 92, 419-431.

Barrett, N. R. (1962). Benign stricture in the lower esophagus. $J$. thorac. cardiovasc. Surg., 43, 703-715.

Belsey, R. (1966). Benign strictures of the oesophagus. Proc. roy. Soc. Med., 59, 932-933.

Bennett, J. R., and Atkinson, M. (1966). Oesophageal acid-perfusion in the diagnosis of precordial pain. Lancet, 2, 1150-1152.

Berne, C. J. (1964). In Hernia, edited by L. M. Nyhus and H. N. Harkins, pp. 496-498. Pitman, London.

Brain, R. (1966). Peptic strictures of the oesophagus associated with duodenal ulcer, and operations for its relief. Proc. roy. Soc. Med., 59, 929-931.

Burge, H. W., Gill, A. M., MacLean, C. D. T., and Lewis, R. H. (1966). Symptomatic hiatus hernia. Thorax, 21, 67-74.

Davidson, J. S. (1968). Hiatal hernia. Postgrad. med. J., 44, 579-585.

Hiebert, C. A., and Belsey, R. (1961). Incompetency of the gastric cardia without radiologic evidence of hiatal hernia. J. thorac. cardiovasc. Surg., 42, 352-362.

Hill, L. D. (1967). Esophageal hiatal hernia. Amer. J. Surg., 113, 94-97.

Johnson, H. Daintree (1968). The Cardia and Hiatus Hernia. Heinemann, London.

Nissen, R. (1964). The treatment of hiatal hernia and esophageal reflux by fundoplication. In Hernia, edited by L. M. Nyhus and $H$. N. Harkins, pp. 488-496. Pitman, London.

Rex, J. C., Andersen, H. A., Bartholomew, L. G., and Cain, J. C. (1961). Esophageal hiatal hernia: a 10-year study of medically treated cases. J. Amer. med. Ass., 178, 271-274.

Skinner, D. B., and Belsey, R. H. R. (1967). Surgical management of esophageal reflux and hiatus hernia. $J$. thorac. cardiovasc. Surg., 53, 33-54.

Tanner, N. C. (1966). Stricture of the lower oesophagus. Proc. roy. Soc. Med., 59, 933.

Thal, A. P., Hatafuku, T., and Kurtzman, R. (1965). New operation for distal esophageal stricture. Arch. Surg., 90, 464-472.

Truelove, S. C., and Reynell, P. C. (1963). Diseases of the Digestive System. Blackwell, Oxford.

Weir, R. D., and Backett, E. M. (1968). Studies of the epidemiology of peptic ulcer in a rural community: prevalence and natural history of dyspepsia and peptic ulcer. Gut, 9, 75-83.

Wolf, B. S. (1967). Diaphragmatic hernia and allied conditions: radiologic aspects. $N . Y$. St. J. Med., 67, 665-667. 